\title{
The Role of Biotechnology for Conservation and Biologically Active Substances Production of Rhodiola rosea: Endangered Medicinal Species
}

\author{
Krasimira Tasheva and Georgina Kosturkova \\ Institute of Plant Physiology and Genetics, Bulgarian Academy of Sciences, 1113 Sofia, Bulgaria \\ Correspondence should be addressed to Krasimira Tasheva, krasitasheva@yahoo.com
}

Received 31 October 2011; Accepted 22 December 2011

Academic Editor: Vidadi Yusibov

Copyright ( $12012 \mathrm{~K}$. Tasheva and G. Kosturkova. This is an open access article distributed under the Creative Commons Attribution License, which permits unrestricted use, distribution, and reproduction in any medium, provided the original work is properly cited.

\begin{abstract}
At present, more than 50000 plant species are used in phytotherapy and medicine. About $2 / 3$ of them are harvested from nature leading to local extinction of many species or degradation of their habitats. Biotechnological methods offer possibilities not only for faster cloning and conservation of the genotype of the plants but for modification of their gene information, regulation, and expression for production of valuable substances in higher amounts or with better properties. Rhodiola rosea is an endangered medicinal species with limited distribution. It has outstanding importance for pharmaceutical industry for prevention and cure of cancer, heart and nervous system diseases, and so forth. Despite the great interest in golden root and the wide investigations in the area of phytochemistry, plant biotechnology remained less endeavoured and exploited. The paper presents research on initiation of in vitro cultures in Rhodiola rosea and some other Rhodiola species. Achievements in induction of organogenic and callus cultures, regeneration, and micropropagation varied but were a good basis for alternative in vitro synthesis of the desired metabolites and for the development of efficient systems for micropropagation for conservation of the species.
\end{abstract}

\section{Introduction}

Resent investigation of the World Health Organization (WHO) recorded increasing utilization of herbs in the medical practice [1]. The European market of medicinal plant preparations and remedies has been stimulated by the national policies for better exploitation of the advantages of the traditional and the alternative medicine $[2,3]$. The short period of time from 1999 to 2001 marked a considerable increase in the medicinal plants trade in many countries: in the Czech Republic by $22 \%$, in Turkmenistan by $100 \%$, and in Bulgaria by $170 \%$. Similarly increasing herbs use in the developed countries was recorded [4]. More than $25 \%$ of the British population is taking them regularly [5]. The business becomes more stable with sales income reaching 5 billion USD for the period of 2003-2004 in Western Europe; 14 billion USD in China for the year of 2005, and 160 million USD in Brazil for the year of 2007.

At present more than 50000 plant species are used in the two major fields: the contemporary phytotherapy and the modern allopathic medicine [4]. World-wide, about $2 / 3$ of those 50000 medicinal plants are harvested from nature [6]. The share of the cultivated plants used in the pharmaceutical industry is quite small, yet, being only $10 \%$ in Europe [5]. The number of natural populations is decreasing progressively leading to local extinction of many species or degradation of their habitats [7]. According to the data of the Food and Agricultural Organization (FAO) at the United Nations annually the flora bares irretrievable losses which destroy the natural resources and the ecological equilibrium [8]. Four thousand to 10000 medicinal species were endangered of disappearing during the last years [6].

Bulgaria is in the leading world positions in export of wild medicinal plants. Annual harvest varies between $15000 \mathrm{t}$ and $17000 \mathrm{t}$. Half of them are collected in the mountains while $80 \%$ of them are exported [9-12]. Bulgarian medicinal plants are famous for their high content of biologically active substances. They are ranked in the first world positions considering quality which is due to the specific climatic and soil conditions of the country [13]. 
However, the constant expansion of herbs trade, the insufficient cultivation fields, and the bad management of harvesting and overharvesting have led to exhaustion of the natural resources and reduction of the biodiversity. To stop the violence against nature, efforts should be directed to both preservation of the plant populations and elevating the level of knowledge for sustainable utilization of these plants in medicine-traditional, alternative, and allopathic [4].

This great issue is in the focus of science which offers different decisions to solve the global problem. Cultivation of the valuable species in experimental conditions is one of the approaches. The latter refers to application of classical methods for multiplication by cuttings, bulbs, and so forth, as well as by biotechnological methods of in vitro cultures and clonal propagation for production of enormous number of identical plants. The micropropagation is considered to have the greatest commercial and iconomical importance [14]. The modern techniques are especially appropriate for species which are difficult to propagate in vivo [15].

Biotechnological methods offer possibilities not only for faster cloning and conservation of the genotype of the plants $[14,16]$ but for modification of their gene information, regulation and expression for production of valuable substances in higher amounts or with better properties $[15,17]$. Application of integrative approaches to cultivation of plant systems could be a basis for future development of new, more effective, safe, and higher-quality products. Biotechnological methods are reliable and provide continuous sources of raw material and natural products for food, pharmaceutical, and cosmetic industries [17-19].

\section{Rhodiola rosea L.: Importance and Characterization}

Rhodiola rosea is one of the endangered medicinal species with outstanding economical importance determined by its roots and rhizomes (Rhadix et Rhizoma Rhodiolae-rose root) utilization in medicine and pharmacy for more than thousands of years.

Golden root extracts have various properties-adaptogenic, antitoxic, antihypoxic. They increase the body's nonspecific resistance and normalize body functions by stimulation of the own-body biochemical and functional reserves. Rose root preparations regulate metabolism, the functions of the central nervous system, the heart, and the hormonal glands [20-23].

The chemical composition of the extracts from the Rhodiola root and rhizomes was studied by East-European research groups mainly [24-30]. A decade of investigation $[31,32]$ revealed evidences about the presence of different biological active substances in the rhizome of golden root unlike some other Rhodiola species.

Six different groups of chemical components with pharmaceutical interest could be found in the roots and rhizomes: (1) phenylpropanoids-alcohol derivatives of the cinnamon acid and glycosides like rosavin (2.1\%) [33], rosin and rosarin (which are classified under the general name of "rosavins") [30, 32, 34-36]; (2) phenylethanoidssalidroside (rhodioloside) (0.8\%), p-tyrosol [37-42]; (3) fla- vonoids_-including rodiolin, rodionin, rodiosin, acetylrodalgin, tricin [32, 34, 43], and tannins 16-18\% [44]; (4) monoterpenes, including rosiridol and rosidarin; (5) triterpenes, such as daucosterol and betasitosterol; (6) phenolic acids such as chlorogenic, hydroxycinnamic, gallic acids [29] and essential oils $[35,45,46]$. All these substances determine the specificity of the Rhodiola extracts. However, the roots have many other substances like phenolic antioxidant, including proanthocyanidins, quercetin, gallic acid, and chlorogenic acid [23, 47].

Rosavins (rosavin, rosarin, and rosin) and the salidroside or rhodioloside, as well as rodiolin, rodonizid, and roziridine are the most important, and are mainly used as active substances for production of medical preparations. Tyrosol is also a crucial active ingredient; though to a less extent than the other two standards. The rosavins complex is specific for Rhodiola rosea unlike salidroside which presents in other Rhodiola species and in some plants from other genera [29, 48].

One of the major results of the research is the detection of differences in the content of biologically active substances in the roots of $R h$. rosea depending on their habitats [40, 42, $48,49]$. Investigation of rose root from different Bulgarian mountains areas indicated the highest amount of salidroside of $1.55 \%$ in Rila mountain sites, and, respectively, the lowest of $0.72 \%$ in Pirin Mountain sites [50]. The stem and the leaves contain less salidroside, while there is no substantial difference in the levels of polyphenols accumulation in the epigeous parts of the plant.

2.1. Taxonomy and Morphology. Rhodiola rosea L. (Sedum roseum (L.) Scop., S. rhodiola DC.), rose root, golden root (Crassulaceae family) is a species, valuable for the world gene fund of herbs (medicinal plants) distinguished among the other 200 species of Rhodiola genus and esteemed for its outstanding pharmacological importance and use.

Rhodiola rosea L. is a succulent herbaceous, perennial, and dioecious plant (having separate male or female plants) with a thick quite branched scaly rhizome (rootstock) with average weight of $70-400 \mathrm{~g}$, but reaching $3.5 \mathrm{~kg}$, too. Root and rhizomes have rose scent. Several shoots grow from the same thick root. The stem is straight, $10-30 \mathrm{~cm}$ in height [51]. The leaves are oblong, elliptic-oblanceolate, or obovate, entire. Inflorescences are corymbiform or capitates, the flowers unisexual, flowers are set from April to August. Propagation is vegetative or by seeds [52].

Golden root grows mainly in the cooler regions of the world-the Arctic, Scandinavia, North Russia, in the mountains of Asia (the Himalayas, the Altai, and the Ural mountains) and Europe (the Alps, the Pyrenees, the Carpathian Mountains), and in other higher mountainous regions (980 to $2000 \mathrm{~m}$ altitude) like those in Bulgaria (the mountains of Sredna Gora, Rila, Pirin, and the Balkan) [53]. This plant prefers the scree, grassy, or rocky slopes, from mountain to subalpine zone of heights up to 2280 meters altitude [54].

Intensive and unscrupulous exploitation of the natural habitats in many countries has resulted in extinction of the species in these regions [55]. This provoked undertaking of a series of nature-protecting measures like (1) cultivation 
under appropriate conditions, (2) protection of the populations in the protected territories, (3) including the species in the Red Books of rare and endangered plant species.

Rhodiola rosea is included in the Red Books of Republic of Buryatia AR, of Yakut ASSR, of Mongolia; "Rare and Extinct Plant Species in Tuva A Republic," "Rare and Extinct Plant Species in Siberia," in Great Britain-Cheffings \& Farrell, in Finland-category "last concerned." Rhodiola rosea in Bulgaria is under protection of the law for biological diversity [56]. Activities concerning the protection and the sustainable use of the plant are described by the Law for medicinal plants [57]. Some Rhodiola rosea populations are included in reservation areas in the states of the Commonwealth of Independent States (CIS) mainly. Rhodiola rosea is successfully cultivated in botanical gardens and centers for introduction in Russia (Saint Petersburg, Gorno-Altaysk, Novosibirsk, Irkutsk, etc.) [58], Finland, and Norway mainly [59].

In Bulgaria, like in the other countries, the number of natural resources of Rhodiola rosea is decreasing progressively. The restoration capacity of the wild-growing plants are quite limited due to the very low, both, seed germination $(5-35 \%)$ and coefficient of vegetative reproduction $[26,60]$. Plants need from 4 to 6 years for optimal development and maximum accumulation of biologically active substances in the rhizomes $[21,60]$.

These data determine the interest towards Rhodiola rosea for establishment of in vitro cultures as initial raw material for the pharmaceutical industry and for the plant conservation.

\section{In Vitro Cultures of Rhodiola rosea $L$.}

Despite the great interest to $R h$. rosea and the wide investigations in the area of phytochemistry, one potential areathat of the plant biotechnologies, remains less endeavored and exploited in comparison to other medicinal species. At present there are many scientific groups in the world working on various medicinal plants like Panax ginseng, Arnica montana, Rauwolfia, and Galanthus [15-17]. In vitro propagation has gained distinguished success, and during the last years it reached large commercial scale, corresponding to the demands of the pharmacological industry [15]. In spite of that, there is not an universal protocol applicable to all species of interest. Usually schemes are established for a particular plant for specific purposes. However, accumulation of experience and knowledge in addition to the empirical approach is a good basis for elaborating desired schemes for the target plants.

Pioneer experiments on golden root in vitro cultures were initiated in the nineties of the last century [61-63]. Next further research was directed to examine the factors important for a successful establishment of callus and organogenic cultures which depends mostly on the interactions of the explant, the nutritious media, the phytoregulators, and the culture conditions on the plant genetic background. However, the optimal combinations of these factors could be determined experimentally for each specific case.

The choice of the explant type is a crucial factor for successful realization of the morphogenic potential of the isola-

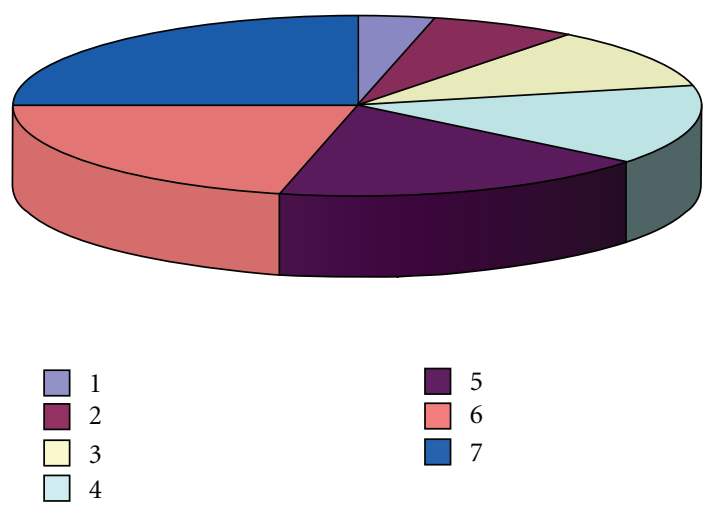

FIGURE 1: The relative shares of the most commonly used explants for initiation of Rhodiola in vitro cultures. Explant were excised from plants growing in their natural environment: (1) leaves, (2) stem, (3) shoot tips and buds, (4) nodes and rhizome buds, (5) axillary buds, (6) hypocotyl, and (7) apical buds and stem nodes from in vitro seedlings.

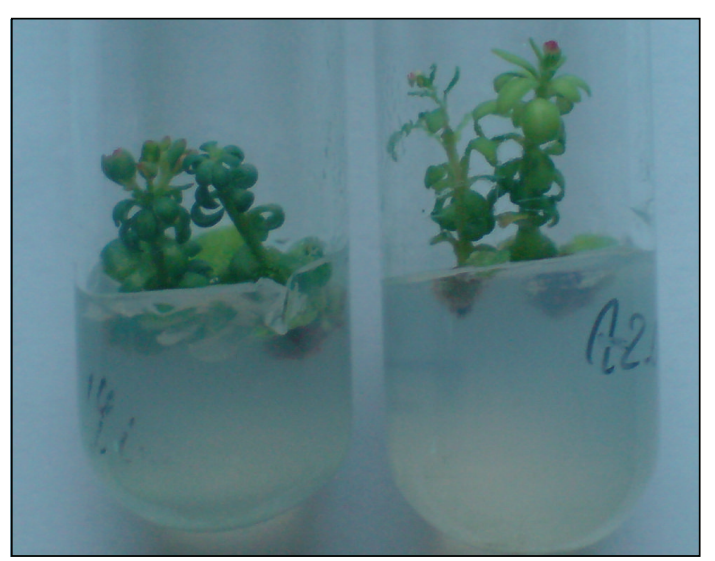

FIgURE 2: Rh. rosea plant regeneration from in vitro seedling apical buds on Murashige and Skoog (MS) [64] basal medium enriched with $2 \mathrm{mg} / \mathrm{L}$ zeatin, $0.2 \mathrm{mg} / \mathrm{L}$ IAA, and $1000 \mathrm{mg} / \mathrm{L}$ casein hydrolysate.

ted cells. The explant could determine the organogenic and the genetic stability of the progeny after cloning. This is the reason for the great number of explants used for initiation of in vitro cultures in $R h$. rosea.

Leaves or leaf disks were preferable explants for callus, bud, and shoot formation [62, 65-68]. Explants of less use were axillary buds [63], stem segments [67,69], shoot tips and buds [69-71], and node and rhizome buds [69, 72] excised from plants growing in their natural environment and in vitro (Figure 1). Apical buds and stem nodes from in vitro seedlings were the object of others' investigations [69, $73,74]$ (Figures 2 and 3). Obtained data reveal that experiments in the different laboratories have contradictory success.

The nutritious media and the phytoregulators are the other very important factors influencing the processes of callogenesis, organogenesis, regeneration, and multiplication in vitro. The chemical composition of the media and its physical 


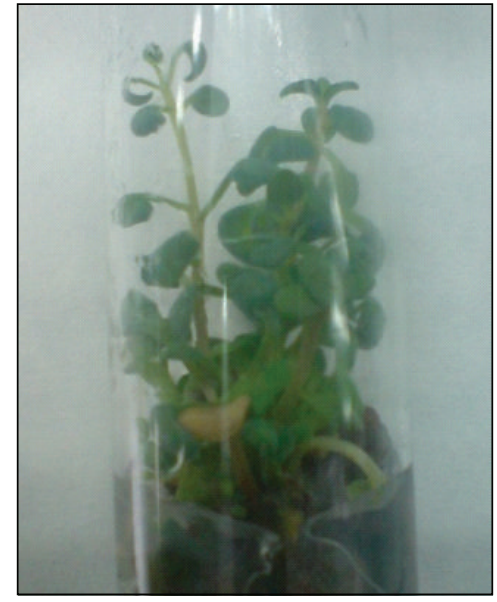

(a)
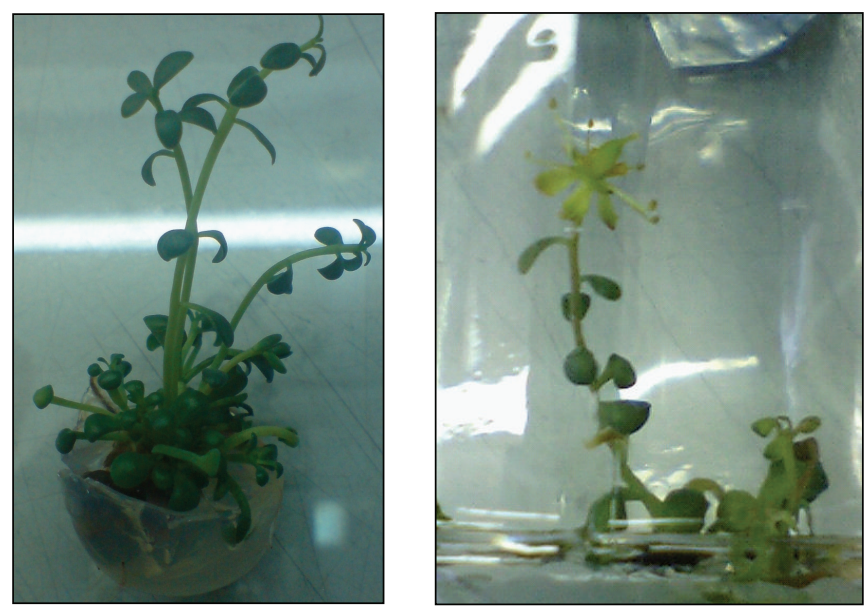

(b)

FIGURE 3: Rh. rosea plant regeneration from in vitro seedling leaf nodes (a); shoot multiplication (b) and flowering regenerant on MS basal medium enriched with $2 \mathrm{mg} / \mathrm{L}$ zeatin, $0.2 \mathrm{mg} / \mathrm{L} \mathrm{IAA}$, and $1000 \mathrm{mg} / \mathrm{L}$ casein hydrolysate.

properties should correspond to the requirements of each stage of culture development $[17,75]$. The test of different recipes of Murashige \& Skoog (MS), Linsmaer \& Skoog, Gamborg, White, and Nitsch \& Nitsch showed that the last one was the best for plant development from shoot tips, while MS medium allowed various responses from different explants [65]. MS medium, compared to these of Litvay and of White, proved to be better for evaluation of morphogenic potential of $R h$. rosea and $R h$. iremelica [70] as well as for callus cultures and regeneration in Tibetan $R h$. rosea [76]. The Murashige and Skoog medium became the most popular one for golden root in vitro cultures. Usually it is supplemented with various growth regulators in different combinations and concentrations. The most commonly used are 6-benzylaminopurine (BAP), indole-3-acetic acid (IAA), 1-naphthyl acetic acid (NAA), indole-3-butyric acid (IBA), and 2,4dichlorophenoxy acetic acid $(2,4-\mathrm{D})[62,65-67,69,70]$ but the effect of zeatin, dimethylaminopurine $(2-\mathrm{iP})$, kinetine, and thidiazuron (TDZ) was examined, too $[69,71-73]$ (Figures 4,5 , and 6 ).

However, the efficiency of the plant growth regulators is in relation to the genetic background which was proven in the experiments with various Rhodiola rosea ecotypes [70]. The best results for revealing the morphogenetic potential could be achieved by the appropriate balance between the explant and the media enriched with phytoregulators and other nutritious supplements and the genotype. These are the three milestones in the experiments of each group aiming at establishment of Rhodiola in vitro cultures. Achievements in induction of organogenic and callus cultures, regeneration, and micropropagation varied, and some examples are presented in this review.

Leaf segments were used in one of the first investigations for induction of shoots and callus formation [62]. The response of this explant type was evaluated on quite a great number (15 variants) of Murashige and Skoog medium [64]. The importance of BA, both for dedifferentiation and
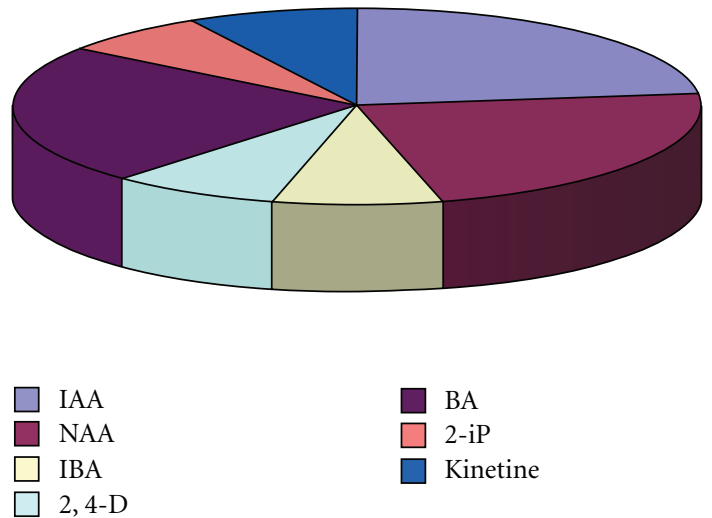

FIGURE 4: The relative shares of the most commonly used plant phytoregulators for Rhodiola callus induction in vitro.

redifferentiation processes was pointed out. This cytokinin in the absence of auxins caused adverse effect on leaf viability and callus formation. However, the ratio between its concentrations and that of IAA and NAA, determined induction of callogenesis and organogenesis. Callus and root formations was stimulated by isomolar levels of $5 \mu \mathrm{M} / \mathrm{L}$ each BA and IAA while shoot formation was more efficient when the BA concentration was higher than the concentration of the auxin NAA $0.5 \mu \mathrm{M} / \mathrm{L}$.

Nearly at the same time quite detailed investigations were performed to study the interaction between two explant types and different nutritious media and growth regulators on the regeneration and callogenesis potential of $R h$. rosea [65]. Using leaf segments and shoot tips different combinations of BA, Kin, IAA, 2,4-D, NAA and 2-iP were tested. The most favorable conditions for shoot formation were shoot tips cultivation for 8 weeks on Nitsch \& Nitsch (NN) medium supplemented with $0.1 \mathrm{mg} / \mathrm{L}$ IAA and $0.1 \mathrm{mg} / \mathrm{L}$ or $1 \mathrm{mg} / \mathrm{L}$ kinetin. The same media favored root formation, too. 

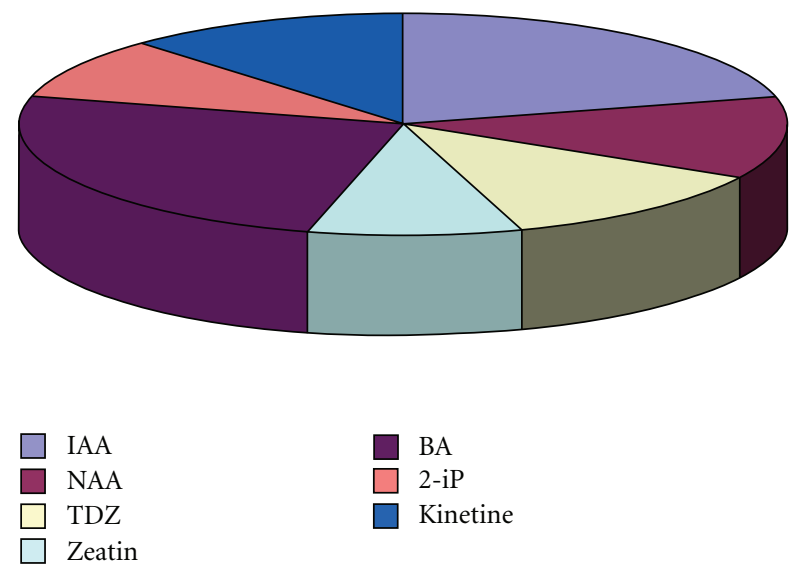

FIgURE 5: The relative shares of the most commonly used plant phytoregulators for Rhodiola bud and shoot induction in vitro.
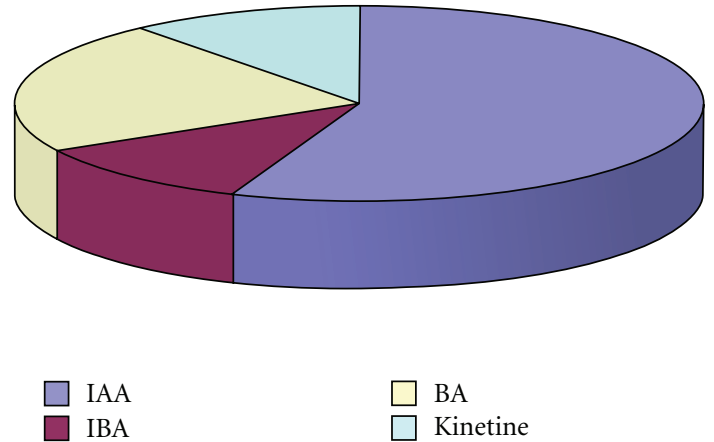

FIGURE 6: The relative shares of the most commonly used plant phytoregulators for Rhodiola root induction in vitro.

However, addition of BA and IBA to NN medium led to lower levels of regeneration and to inhibition of the growth when NAA was included. Complete suppression of development of explants from leaf, hypocotyls, and shoot tips was observed on Linsmaer \& Skoog medium containing 2-iP and IAA. Callogenesis was induced only by leaf segments plated on Gamborg-B5, Gibco, and MS media. However, adequate growth was observed on the last medium containing $\mathrm{BA}$ and NAA, or BA and IBA.

A different approach was used in other experiments [66]. Suitable plant material for initiation of shoot cultures was seeds which before in vitro germination were treated with low temperature of $2-4^{\circ} \mathrm{C}$ for a period of 4 and 6 months or with $0.02 \% \mathrm{GA}_{3}$ for 24 hours. These procedures replaced successfully the seed stratification. Stem segments, stem apex, and leaf explants excised from the seedlings were cultured on MS medium enriched with BA and IAA in different ratio of concentrations from $1 \mathrm{mg} / \mathrm{L}$ to $3 \mathrm{mg} / \mathrm{L}$ of the cytokinin and from $0.8 \mathrm{mg} / \mathrm{L}$ to $2.6 \mathrm{mg} / \mathrm{L}$ of the auxin. The most efficient direct organogenesis was from leaf explants on MS medium supplemented with $2 \mathrm{mg} / \mathrm{L}$ BAP and $1.7 \mathrm{mg} / \mathrm{L}$ IAA.

Seeds and rhizomes from three ecotypes from the High Altai and South Ural region served as the explant source to study induction of callogenesis and organogenesis [70]. Explant development was observed on MS media containing various phytoregulators (BAP, IAA, NAA, IBA, 2,4-D). Vigorous callus formation of $86 \%$ of the explants was observed on MS medium enriched with 0.1-0.2 mg/L IAA. The optimal combination for multiple bud formation in Rhodiola rosea from stem segments was BAP and IAA in concentrations of $0.2 \mathrm{mg} / \mathrm{L}$ and $0.1 \mathrm{mg} / \mathrm{L}$, respectively, while for Rhodiola iremelica the efficient concentrations were lower- $0.1 \mathrm{mg} / \mathrm{L}$ BAP and $0.05 \mathrm{mg} / \mathrm{L}$ IAA. Differences in ecotype appeared to be also an important factor influencing the processes of efficient callogenesis and organogenesis. Regenerants were initially adapted in vermiculite for two weeks in conditions of high humidity (85-90\%) and later plants were transferred to mixture of soil, peat, and vermiculite in proportion of $1: 1: 1$. Plantlets revealed considerable differences (from 10\% to $95 \%)$ in the survival rate during the process of adaptation. In the later experiments [76] the effect of $R h$. rosea extracts on the morphogenic abilities of $R h$. rosea and Rh. iremelica were studied. Addition of $5 \%$ or $10 \% \mathrm{v} / \mathrm{v}$ liquid extracts in the MS medium provoked different in vitro responses. Bud induction was stimulated by the lower concentration and inhibited by the higher ones leading to formation of 8.5 shoots from the explants in the first case and 1.1 in the second case.

In comparison to the previously described investigations with the Altai ecotype of Rhodiola rosea the optimal concentrations of the cytokinin BAP were 10-15-fold higher for induction of in vitro cultures from immature leaves explants from a Tibetan ecotype of golden root [67]. The authors note interaction between the growth regulators and the illumination of the cultures. Two mg/L BA and $0.2 \mathrm{mg} / \mathrm{L} \mathrm{NAA}$ added to the MS medium stimulated formation of incompact callus tissue. However, when explants were cultivated under dark conditions, higher concentrations of the same phytoregulators $3 \mathrm{mg} / \mathrm{L} \mathrm{BA}$ and $0.25 \mathrm{mg} / \mathrm{L}$ NAA were more efficient. MS medium containing $2 \mathrm{mg} / \mathrm{L} \mathrm{BA}$ and $0.25 \mathrm{mg} / \mathrm{L}$ NAA induced shoot multiplication while rooting was induced on MS medium containing $0.5 \mathrm{mg} / \mathrm{L}$ or $1 \mathrm{mg} / \mathrm{L}$ IAA.

Recently [71] in vitro micropropagation of rose roots in a RITA bioreactor system was reported for the first time. Three clones were obtained from in vitro germinated seedlings of wild Finland golden root. The effect of two stimulators of organogenesis was studied. Two to four $\mu \mathrm{M}$ thidiazuron stimulated shoot induction but inhibited shoot growth while 1-2 $\mu \mathrm{M}$ zeatin favored increasing shoot size and leaf number per shoot. The clones differed significantly in respect to multiplication rate. One of them was distinguished for its high coefficient of shoot formation per explant on solidified medium enriched with $2 \mu \mathrm{M}$ zeatin. In the bioreactor thidiazuron maintained rapid shoot proliferation at quite concentration $(0.5 \mu \mathrm{M})$ but induced hyperhydracity at more than $0.5 \mu \mathrm{M}$. However, hyperhydracity was abolished when shoots were transferred for 4 weeks on gelled medium enriched with 1-2 $\mu \mathrm{M}$ zeatin. Shoots formed roots for 5-6 weeks on BM medium without phytoregulators. Most of the regenerants (85-90\%) survived when transferred to soil. After acclimatization, the plants growing in the green house had normal shoot and leaf morphology. 

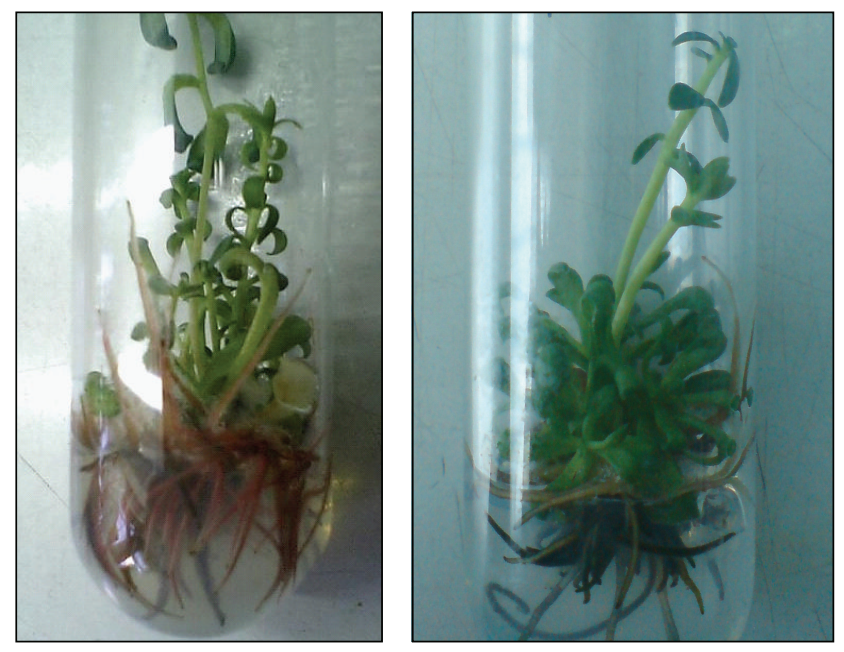

FIGURE 7: Induced rhizogenesis and propagation in $R h$. rosea regenerated plants on MS medium enriched with $2.0 \mathrm{mg} / \mathrm{L}$ IBA, $0.2 \mathrm{mg} / \mathrm{L}$ IAA, and $0.4 \mathrm{mg} / \mathrm{L} \mathrm{GA}_{3}$ [69].

An extensive research with Bulgarian $R h$. rosea ecotype brought the development of a complete system for obtaining callus cultures, shoot induction and multiplication, micropropagation, and reintroduction of regenerants to the natural environment of the rose root. Success was based on the investigations of the interaction between numerous explant types, media supplements, and culture conditions. In the initial experiments $[73,74]$ apical buds and stem nodes excised from in vitro germinated seedlings/plants were used. Another series of experiments [69] examined the morphogenic potential of five types of explants obtained from wildgrowing plants (apical buds, adventitious shoots, stem explants, rhizome buds, and rhizome segments). Different in vitro responses were observed-formation of plantlets, leaf rosette, various types of callus (compact green, pale, soft liquidy) and callus degeneration without bud formation. In another series of experiments the authors cultivated explants excised from 15-25 mm high seedlings-apical bud, stem segment with leaf node, and explants excised from the seedling root basal area. The stem segment with leaf nodes and apical buds were the best explants for in vitro propagation. Morphogenic potential was studied on MS basal medium containing a range of phytoregulator combinations, including basically benzyl adenine, kinetin, zeatin, 2-iP, 2,4-D, NAA, and IAA. Excised leaf nodes and apical buds from seedlings cultured in vitro proved to be a good solution in the investigations for overcoming the problems when working with wild plants. The both explants regenerated shoots with highest efficiency of more than $80 \%$ on zeatin containing media. The zeatin and the $2-\mathrm{iP}$, compared to kinetin and BAP, stimulated growth and formation of shoots from seedling leaf nodes and apical buds. The significance of zeatin for numerous bud/shoot formations was pointed out. It was interesting to note that the coefficient of propagation varied during the different seasons. Highest level of proliferation was observed in May-June, when the shoots per explant were 6.78. During the cold seasons multiplication was relatively lower-2.11 shoots per explant [77].
Rhizogenesis was stimulated by IBA in increasing concentrations up to $2 \mathrm{mg} / \mathrm{L}$ and was most efficient when IBA and IAA were applied in combination (Figure 7). The regenerants $3-5 \mathrm{~cm}$ in height which had $2-3 \mathrm{~cm}$ long roots were transferred to pots containing a mixture of soil: peat: perlite in a ratio $3: 1: 1$ and were maintained for 20 days for adaptation in special chambers (Figure 8). Acclimatization of rooted golden root plantlets into the greenhouse was successful up to $70 \%[69,77]$.

In vitro obtained plants were phytochemical analyzed for the presence of biologically active substances which were not found in the roots of one-month-old regenerants in test tubes (unpublished data). However, salidroside was produced in the rhizome and roots of one- and two-year old regenerants grown in the mountains [78] and in the green house (Figure 9) (unpublished data). The results were promising as far as salidroside content of regenerants was higher than that of the wild plants.

In vitro plants obtained on different culture media were subjected to cytological analysis. However, procedures for squash preparations were modified to be applicable to meristematic cells of root tips of Rhodiola rosea regenerants. The chromosome number in all samples was $2 n=22$, which confirmed the diploid level of plant regenerants and cytogenetic identity with the wild-type (Figure 10) [79]. Concerning flowers, leaves, stem, and rhizomes no differences were recorded between the wild plants and the regenerated plants grown for 1 and 2 years ex vitro in the adaptation room, in the green house, and in the mountain.

As a result of the experiments efficient schemes for regeneration and micropropagation of $R h$. rosea were established, despite the difficulties working with wild species. The different schemes for efficient micropropagation, utilizing a range of media and several types of explants, allow flexibility in the investigations. These schemes varied in time duration, labor consumption, and costs. 


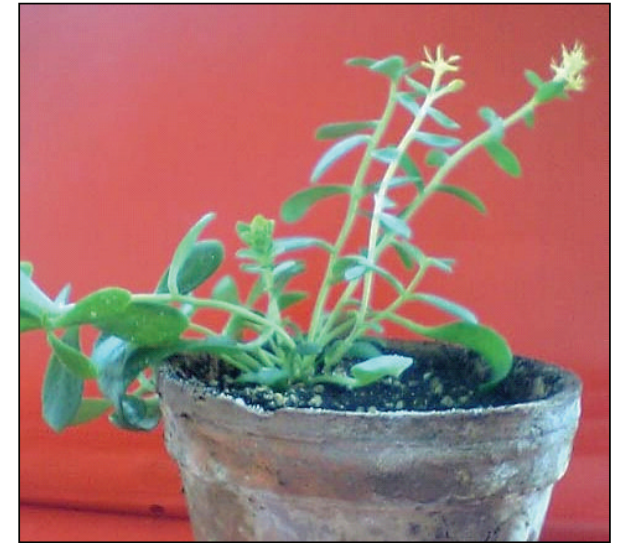

Figure 8: Adaptation of $R h$. rosea regenerants in mixture of perlite, peat, and soil [69].

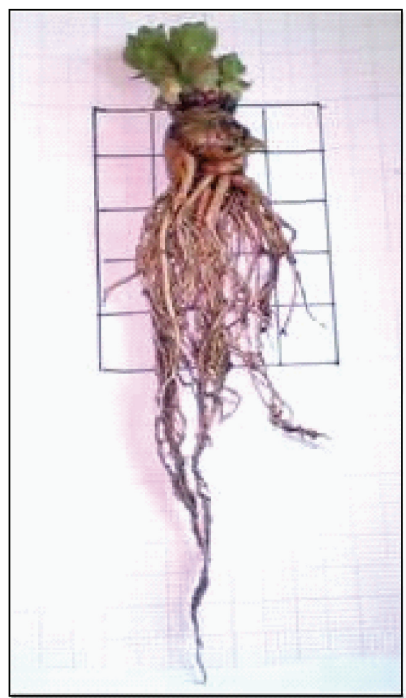

FIgURE 9: Roots and rhizomes of in vitro regenerated plant cultivated two years in the green house [79].

A recommendable protocol could be the following one:

(1) seed decontamination by EtOH for 3 min followed by $20 \% \mathrm{v} / \mathrm{v}$ bleach for $15 \mathrm{~min}$ and germination on MS media containing 5-100 mg/L gibberellic acid;

(2) shoot multiplication from leaf nodes from seedlings or regenerants on MS enriched either with $2 \mathrm{mg} / \mathrm{L}$ zeatin, $0.2 \mathrm{mg} / \mathrm{L} \mathrm{IAA}$, and $1000 \mathrm{mg} / \mathrm{L}$ casein hydrolysate or with $0.2 \mathrm{mg} / \mathrm{L}$ zeatin and $0.2 \mathrm{mg} / \mathrm{L} \mathrm{IAA} \mathrm{(or}$ for a longer period on MS with $1 \mathrm{mg} / \mathrm{L}$ BA and $0.1 \mathrm{mg} / \mathrm{L} \mathrm{IAA}$ or $0.5 \mathrm{mg} / \mathrm{L} \mathrm{BA}$ and $0.1 \mathrm{mg} / \mathrm{L}$ ); rooting of plantlets on MS with addition of either $0.2 \mathrm{mg} / \mathrm{L}$ IAA, $2.0 \mathrm{mg} / \mathrm{L} \mathrm{IBA}, 0.4 \mathrm{mg} / \mathrm{L} \mathrm{GA}_{3}$ or $0.2 \mathrm{mg} / \mathrm{L} \mathrm{IAA}$, $2.0 \mathrm{mg} / \mathrm{L} \mathrm{IBA}, 0.1 \mathrm{mg} / \mathrm{L} \mathrm{GA}_{3}$;

(3) in vivo adaptation in a combination of perlite, peat, and soil in ratio of $1: 1: 3$.

The whole process could take about three months. For this period more than 100 regenerated plantlets could be

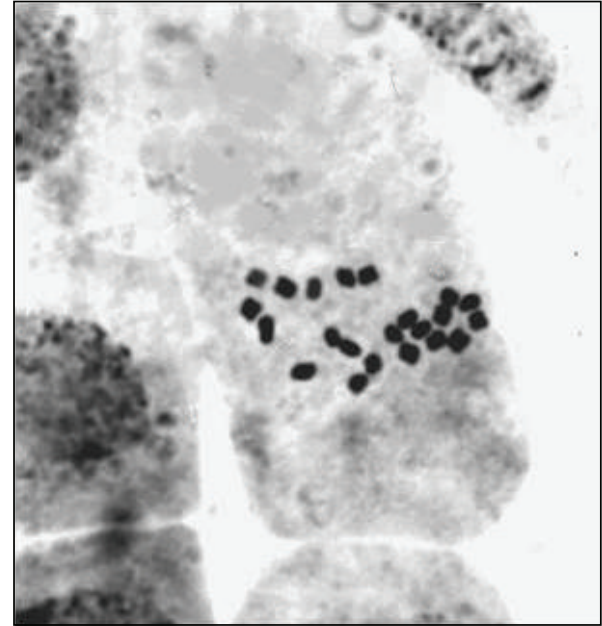

FIGURE 10: "Squash" preparation of meristematic cells of root tips excised from in vitro plant regenerants of Rhodiola rosea having diploid chromosome number of $2 n=22$ [79].

propagated from one seedling of rose root. Each regenerant could give three to five explants for further clonal propagation.

Remarkable success of this work was the adaptation of in vitro obtained regenerants to the wild high mountain conditions which was not reported by others. This success allows restoration of the habitats and conservation of germplasm of the endangered medicinal species rose root. Accumulation of biomass by micropropagation and salidroside synthesis by in vitro regenerants confirm the potential of this ecology friendly biotechnological method for the production of valuable substances from Rhodiola rosea. The present conclusions were proved by authors' further phytochemical analysis of salidroside, rosavin, rosin, and rosarin by HPLC detection in roots and rhizomes of in vitro plants, reintroduced in nature (unpublished data).

\section{Potential of Biotechnological Methods for Increasing Biologically Active Substances Production by $R$ hodiola rosea}

The plants are traditional source of quite a big number of biologically active substances used in the pharmaceutical industry. The most valuable phytochemicals are products of the secondary metabolism. Most of them have complicated structure which makes their chemical synthesis very difficult and even impossible. Plant in vitro cultures are able to produce and accumulate a lot of substances esteemed by the pharmacy and the medicine.

After establishment of in vitro cultures, research continues for their implementation in practice. Plant in vitro cultures offer possibilities for production of valuable secondary metabolites in bioreactors, for manipulation of the metabolic pathways and metabolic engineering, and for biotransformation. The latter is one of the key mechanisms for improvement of biologically active substances production in Rhodiola rosea callus and cell suspension cultures. However, 
there are not so many reports on Rhodiola in vitro cultures used for a production of biologically active substances and for a determination of the optimal parameters for their synthesis in vitro.

The possibilities of cell suspension cultures initiated from leaf explant callus were studied [80] for increasing the synthesis of rosavin and other cinnamyl glycosides after addition of transcinnamyl alcohol (optimal concentration of $2.5 \mathrm{mM}$ ) into the liquid MS medium. For about 3 days more than $90 \%$ of the alcohol was transformed by the cells into various unidentified products. However, one of them, 3-phenyl-2-propenyl-O- $\left(6^{\prime}-\mathrm{O}-\alpha^{\prime}\right.$-L-arabinoryranosyl)- $\beta$-D-glucopyranoside, found in the intracellular spaces, was defined as potential rozavin by very precise methods. Both green and yellow strains of cell cultures were able to glycosylate trans-cinnamyl alcohol into rosavin with yield of 0.03 to $1.01 \%$ cell dry weight.

The effect of different precursors of biologically active substances on the biomass and the metabolite production was studied in Rhodiola compact callus aggregates in liquid medium [81, 82]. Cinnamyl alcohol concentrations up to $0.1 \mathrm{mM}$ in media did not bring to a significant deviation from the control; 2 to $5 \mathrm{mM}$ changed slightly callus color from dark to light green. In these cultures rosin content was elevated to $1.25 \%$ dry weight while rosavin was $0.083 \%$ dry weight. Cinnamyl alcohol induced synthesis of four new products, too. Tyrosol from $0.05 \mathrm{mM}$ and $2 \mathrm{mM}$ did not influence callus growth while concentrations of $3 \mathrm{mM}$ up to $9 \mathrm{mM}$ caused decrease in biomass production. Two $\mathrm{mM}$ of tyrosol were the optimal levels for salidroside production reaching $2.72 \%$ dry weight. Addition of glucose had no positive effect on salidroside accumulation but doubled the rosin production.

Callus tissues cultivated on solid media could produce active substances characteristic for the species [83]. Addition of yeast extract in the media doubled salidroside content (from $0.8 \%$ to 1.4 ) and was twice as high as in five-yearold roots of the intact plants. In the later experiments [84] callus induced from axillary buds or from seedling hypocotyls transformed exogenous cinnamyl alcohol into rosin. However, the biotransformation process was more efficient in the hypocotyl callus where the application of $2.5 \mathrm{mM}$ cinnamyl alcohol resulted in the increase of rosin content up to $1056.183 \mathrm{mg} / 100 \mathrm{~g}$ on solid medium and $776.330 \mathrm{mg} / 100 \mathrm{~g}$ in liquid medium. Callus tissue obtained from axillary buds and treated in the same way produced rosavin in a higher concentration of $92.801 \mathrm{mg} / 100 \mathrm{~g}$ and reached $20 \%$ of the amount produced by roots [85]. The extract enriched in rosavins (after transformation) showed the inhibition of behavioral activity of the tested animals — rats.

Induction of callogenesis was successful [86] from leaf explants, isolated from in vitro propagated plants, on MS media enriched with BAP in concentration from $0.5 \mathrm{mg} / \mathrm{L}$ to $2.0 \mathrm{mg} / \mathrm{L} ; 2-\mathrm{iP}-0.3$ and $3.0 \mathrm{mg} / \mathrm{L} ; 2,4-\mathrm{D}$ - from 0.1 to $2.0 \mathrm{mg} / \mathrm{L}$; IAA $-0.2,0.3$ and $1.0 \mathrm{mg} / \mathrm{L} ; \mathrm{NAA}-0.5,1.0$, $1.5 \mathrm{mg} / \mathrm{L} ;$ glutamine- $150 \mathrm{mg} / \mathrm{L}$ and casein hydrolysate $1000 \mathrm{mg} / \mathrm{L}$. The highest response to formation of callus $(62.85 \%$ and $73.17 \%)$ was observed on two media-con- taining $1 \mathrm{mg} / \mathrm{L}$ BAP and either $1 \mathrm{mg} / \mathrm{L}$ or $0.5 \mathrm{mg} / \mathrm{L} 2,4-\mathrm{D}$ (Figure 11).

Callogenesis was not observed in any of the variants containing 2-ip and most of the variants containing NAA. In this pioneer study optimal combinations and concentrations of phytoregulators were determined for efficient induction and maintaining of callus amenable for long-term cultivation (6 months) (Figure 12).

Total phenolic/flavonoid content and radical scavenging activity was determined in calli. Antioxidant properties were influenced by the composition of the cultivation media. Relationship between the callus color/structure/texture and the secondary metabolite amounts was not significant. Linear correlation between the total phenolic/flavonoid content and the scavenging activity was observed. Bioinformatics prognosis for the optimal recipes of the nutrition media was made based on the analysis of the data obtained in the biological experiments (unpublished data). This study is a pioneering one concerning establishment and maintaining of Bulgarian golden root callus cultures and determination of their phytochemical properties and could be a basis for in vitro metabolic engineering and biotransformation for alternative production of valuable substances.

\section{In Vitro Cultures of Rhodiola Genus}

Genus Rhodiola consists of 200 polymorphic species. However, less than 20 Rhodiola species including $R h$. alterna, Rh. brevipetiolata, Rh. crenulata, Rh. kirilowii, Rh. quadrifida, Rh. sachalinensis, and Rh. sacra have pharmacological importance for production of medications [20]. All species of the genus contain different quality of salidroside-one of the basic components of the biologically active complex. Biotechnological research focuses mainly on the species distinguished for their high levels and quality of the substances, valuable for the pharmacological industry. Targets of the experiments are induction of callus and organogenic cultures followed by plant regeneration aiming at alternative in vitro synthesis of the desired metabolites and at development of efficient systems for micropropagation for conservation of the species.

The possibility for induction and maintaining of callus cultures was studied [87] in Rhodiola quadrifida, a species used in traditional Chinese medicine for more than 1000 years. Callus induction was induced on MS medium enriched with 2,4-D (1.0 mg/L), NAA (2.0 mg/L), BA (0.5 mg/L), and kinetin $(0.1 \mathrm{mg} / \mathrm{L})$ and maintained on the same basal medium supplemented with 2,4-D (1.0 mg/L), 6-BA $(0.1 \mathrm{mg} / \mathrm{L})$, and kinetin $(0.5 \mathrm{mg} / \mathrm{L})$. Analysis of one-month-old callus showed that the nondifferentiated tissues were able to produce salidroside. The authors underlined the role of 2,4-D and BA for production of biologically active substances. Similar observations about the role of the explant, the temperature of cultivation and the pretreatment duration were made in another work [88] on salidroside synthesis in callus obtained from leaf and stem segments of Rhodiola kirilowii.

Experiments on callus induction followed by plant regeneration of Rhodiola coccinea [89] revealed the importance of callus characteristics for their morphogenic abilities. 

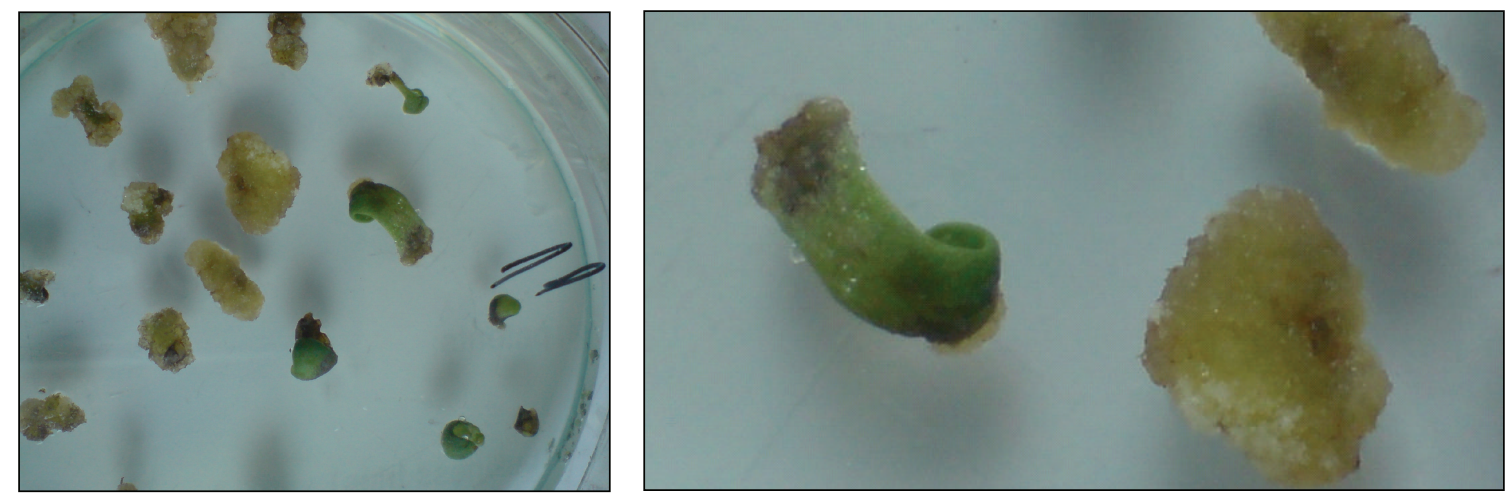

(a)

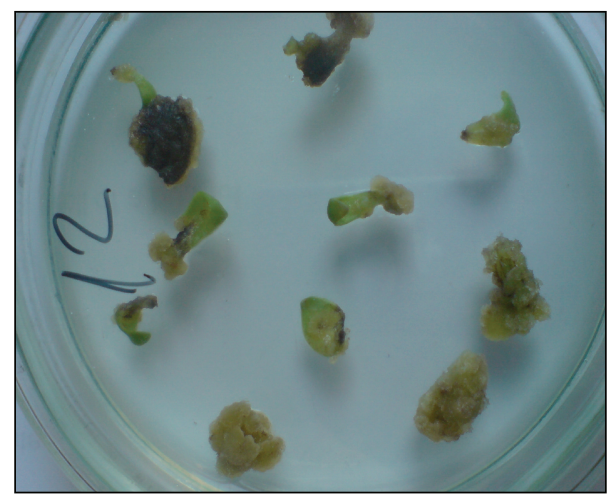

(b)

FIGURE 11: Callus cultures cultivated for 40 days on different media: variant (a) MS medium enriched with $1 \mathrm{mg} / \mathrm{L}$ BAP, $0.5 \mathrm{mg} / \mathrm{L}$ NAA and $1000 \mathrm{mg} / \mathrm{L}$ casein hydrolysate; variant (b) MS medium containing $0.5 \mathrm{mg} / \mathrm{L}$ BAP and $1 \mathrm{mg} / \mathrm{L} \mathrm{IAA}$.

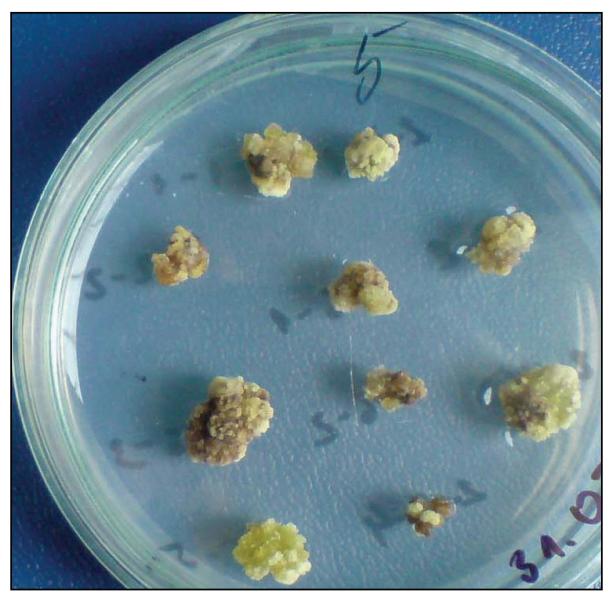

(a)

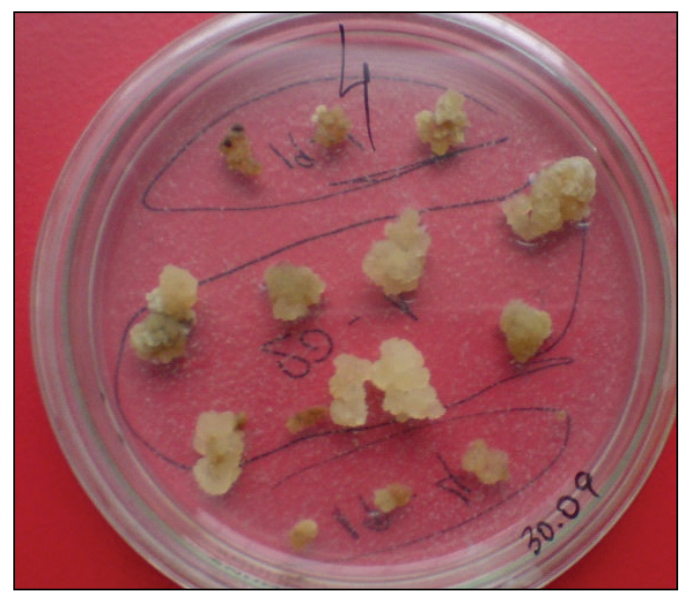

(b)

FIGURE 12: Callus growth after the 3rd passage on different media: variant (a) MS medium enriched with 0.5 mg/L BAP and $1 \mathrm{mg} / \mathrm{L} 2,4-\mathrm{D}$; variant (b) MS medium enriched with $1 \mathrm{mg} / \mathrm{L}$ BAP and $0.5 \mathrm{mg} / \mathrm{L}$ 2,4-D.

Only one out of the three callus types were embryogenic. The latter was induced on MS medium containing BA $(0.5 \mathrm{mg} / \mathrm{L})$ and IAA $(2.0 \mathrm{mg} / \mathrm{L})$. Differentiation and shoot formation was possible by including BA $(0.05 \mathrm{mg} / \mathrm{L})$ and IAA $(0.5 \mathrm{mg} / \mathrm{L})$ in the medium. Five callus types using different explants from root, stem, leaves, and cotyledons of Rhodiola sachalinesis A. Bor. were obtained, too [90]. MS medium containing the phytoregulators BA $3 \mathrm{mg} / \mathrm{L}$, NAA $0.3 \mathrm{mg} / \mathrm{L}$, and temperature of $21-25^{\circ} \mathrm{C}$ were suitable for callus induction. The same species was an object of other authors [91] who succeeded to 
induce callus formation (with yellow, green, and red colors) in $88.33 \%$ of the leaf explants. BA $(2.0 \mathrm{mg} / \mathrm{L})$ and NAA $(0.5 \mathrm{mg} / \mathrm{L})$ were also the effective phytoregulators included in MS medium. The authors found out that only green callus was able to form buds on MS medium with lower concentrations of the same phytoregulators BA $(1.0 \mathrm{mg} / \mathrm{L})$ and NAA $(0.1 \mathrm{mg} / \mathrm{L})$. However, induction of organogenesis was at comparatively low level $(21.33 \%)$ and needed longer period of time of 50 days. Despite this regenerated plantlets were rooted on half strength MS medium. Cryopreservation of calli induced from seedling explants of the same species Rhodiola sachalinesis was successful achieved [92]. The recovery of fresh and green tissues was possible for 6 weeks on nutrient medium containing BA $2.0 \mathrm{mg} / \mathrm{L}$ and NAA $0.5 \mathrm{mg} / \mathrm{L}$. Rhodiola sachalinesis was an object in the sophisticated experiments of obtained protoplast cultures [93]. Mesophyll protoplasts were isolated from leaves of in vitro regenerated plants. The protoplasts which regenerated cell wall, divided to form colonies and calli for a period of 40 days on MS medium enriched with $2,4-\mathrm{D}-1.0 \mathrm{mg} / \mathrm{L}$, zeatin $-0.5 \mathrm{mg} / \mathrm{L}$, $0.5 \mathrm{M} / \mathrm{L}$ mannitol, and casein hydrolysate $500 \mathrm{mg} / \mathrm{L}$ were transferred to poorer medium containing only BA and NAA $(1.0 \mathrm{mg} / \mathrm{L}$ and $0.1 \mathrm{mg} / \mathrm{L}$, resp.). Organogenesis was induced and buds appeared after the p-calli. The shoots developed formed roots on half strength MS medium.

System for in vitro cultivation of Rhodiola sachalinensis callus aggregates for production of salidroside was established [94]. Its biosynthesis was in standard levels, making the system promising for alternative production of the valuable metabolite.

The possibility for in vitro propagation of four Rhodiola species-Rh. crenulata, Rh. yunnanensis, Rh. fastigata, and $R h$. sachalinesis using two types of explants was studies [68]. Stem explants were more suitable for bud induction from $R h$. crenulata, while leaf material was more efficient for organogenesis in the other three species. The genotype and the phytohormones were important for the efficiency of the regeneration. The optimal combination of phytoregulators for organogenesis in Rh. crenulata and Rh. yunnanensis was $2.5 \mathrm{mg} / \mathrm{L}$ BA and $0.1 \mathrm{mg} / \mathrm{L}$ NAA which stimulated bud formation in $71 \%$ and $84 \%$ in Rh. crenulata and Rh. yunnanensis, respectively. The medium containing the higher concentrations of NAA $(0.5 \mathrm{mg} / \mathrm{L})$ and BA $(2.5 \mathrm{mg} / \mathrm{L})$ was more appropriate for $R h$. fastigata and $R h$. sachalinesis bud formation $80 \%$ of the cases. The shoots from the last two species formed roots easily ( $87 \%$ and $73 \%$, resp.) on medium containing IBA. Regenerants from $R h$. fastigata were successfully adapted for further in vivo development in soil reaching survival rate of $66 \%$.

In vitro cultures of Rhodiola crenulata aiming at establishment of technology for in vitro multiplication of the species were developed [95]. Different explants from wild-growing plants were cultivated on MS basal media with various combinations of plant growth regulators: leaf discs on BA $2.0 \mathrm{mg} / \mathrm{L}$ and IAA $0.2 \mathrm{mg} / \mathrm{L}$; flower buds on $2.0 \mathrm{mg} / \mathrm{L}$ kinetin; stem nodes on $2.0 \mathrm{mg} / \mathrm{L} \mathrm{BA}$ and $1.0 \mathrm{mg} / \mathrm{L}$ IAA; stem explants on $2.0 \mathrm{mg} / \mathrm{L}$ kinetin and $1.0 \mathrm{mg} / \mathrm{L}$ IAA. Leaf explants proved to be the most suitable for in vitro development with $100 \%$ shoot induction on MS medium containing $0.2 \mathrm{mg} / \mathrm{L} \mathrm{NAA}$.
The other explant types did not show any development for the adequate period of time. The authors put the basis for micropropagation of $R h$. crenulata.

Accumulation of biomass through micropropagation and the production of biologically active substances in in vitro cultures confirm the potential of this environmentally friendly technology to be used for production of Rhodiola valuable substances.

\section{Conclusion}

Plant biotechnologies of Rhodiola rosea and other Rhodiola species have marked considerable success for their short historical period of 20 years. The first investigations on the factors important for the initiation of in vitro cultures were deepened and broadened and led to the establishment of complete schemes for micropropagation and systems for production of biologically active substances. During the last years more groups have been involved in the research. The number of examined ecotypes and genotypes of golden root has been increasing and has been covering more Rhodiola species. More up-to-date approaches and sophisticated instrumentation have been used which would bring further success to the alternative biosynthesis of valuable Rhodiola metabolites and to protection of this precious rare endangered medicinal plant.

\section{Acknowledgment}

Research was supported by National Science Fund of Bulgaria-Project for Junior Scientists DMU 03/55 (leader K. Tasheva).

\section{References}

[1] K. Matthys, J. Julsing, W. Quax, and O. Kayser, "The Engineering of medicinal plants: prospects and limitations of medicial plant biotechnology," in Medicinal Plant Biotechnology from Basic Research to Industrial Applications, O. Kayser and W. J. Quax, Eds., pp. 1-8, Wiley-VCH/Vergal GmbH \& Co., Weinheim, Germany, 2007.

[2] National policy on traditional medicine and regulation of herbal medicines, Report of a WHO global survey, World Health Organization, Geneva, Switzerland, May 2005, http://apps.who.int/medicinedocs/pdf/s7916e/s7916e.pdf.

[3] The World Medicines Situation 2011, Traditionl medicines: Global situation, issues and challenges, World Health Organization, Geneva, Switzerland, 3rd edition, 2011, http://www .who.int/medicines/areas/policy/world_medicines_situation/ WMS_ch18_wTraditionalMed.pdf.

[4] WHO, 2010, http://www.who.int/mediacentre/factsheets/fs134/en/.

[5] G. Vines, "Herbal harvests with a future: towards sustainable sources for medicinal plants," Plantlife International, 2004, http://www.plantlife.org.uk/.

[6] R. Edwards, "No remedy in sight for herbal ransack," New Scientist, vol. 181, no. 2429, pp. 10-11, 2004.

[7] P. H. Canter, H. Thomas, and E. Ernst, "Bringing medicinal plants into cultivation: opportunities and challenges for biotechnology," Trends in Biotechnology, vol. 23, no. 4, pp. 180$185,2005$. 
[8] FAO, 2010, http://www.fao.org/biodiversity/2010-international-year-of-biodiversity/en/.

[9] A. Vitkova and L. Evstatieva, "Spread and resources of medicinal plants in NP 'Rila', in Proceedings of the International Interdisciplinary Conference on Medicinal plants-Solution 2000, pp. 79-87, Sofia, Bulgaria, June 1999.

[10] L. Evstatieva and R. Hardalova, "Conservation and sustainable use of medicinal plants in Bulgaria," Medicinal Plant Conservation, vol. 9-10, pp. 24-28, 2004.

[11] L. Evstatieva, "A review of the cultivation of endangered medicinal plants in Bulgaria," Annuire de l'Universite de Sofia "St. Kl. Ohridski" Faculte de Biologie Livre 2 Botanique, vol. 97, pp. 45-52, 2006.

[12] L. Evstatieva, R. Hardalova, and K. Stoyanova, "Medicinal plants in Bulgaria: diversity, legislation, conservation and trade," Phytologia Balcanica, vol. 13, no. 3, pp. 415-427, 2007.

[13] M. Mladenova, "Bulgaria-the most exporter of medicinal plants in Europe"', in Proceedings of the International Interdisciplinary Conference on Medicinal Plants-Solution 2000, pp. 110-117, Sofia, Bulgaria, June 1999.

[14] L. Tripathi and J. N. Tripathi, "Role of biotechnology in medeicnal plants," Tropical Journal of Pharmaceutical Research, vol. 2, no. 2, pp. 243-253, 2003.

[15] M. Y. Khan, S. Aliabbas, V. Kumar, and S. Rajkumar, "Resent Advances in Medcinal Plant Biotehology," Indian Journal of Biotechnology, vol. 8, pp. 9-22, 2009.

[16] R. Verpoorte, A. Contin, and J. Memelink, "Biotechnology for the production of plant secondary metabolites," Phytochemistry Reviews, vol. 1, no. 1, pp. 13-25, 2002.

[17] S. Ramachandra Rao and G. A. Ravishankar, "Plant cell cultures: chemical factories of secondary metabolites," Biotechnology Advances, vol. 20, no. 2, pp. 101-153, 2002.

[18] S. M. Nalawade, A. P. Sagare, C. Y. Lee, C. L. Kao, and H. S. Tsay, "Studies on tissue culture of Chinese medicinal plant resources in Taiwan and their sustainable utilization," Botanical Bulletin of Academia Sinica, vol. 44, no. 2, pp. 79-98, 2003.

[19] K.M. Julsing, W. J. Quax, and O. Kayser, “The engineering of medicinal plants: prospects and limitations of medicinal plant biotechnology," in Medicinal Plant Biotechnology: From Basic Research to Industrial Applications, O. Kayser and W. J. Quax, Eds., pp. 1-8, Wiley, 2007.

[20] G. S. Kelly, "Rhodiola rosea: a possible plant adaptogen," Alternative Medicine Review, vol. 6, no. 3, pp. 293-302, 2001.

[21] R. P. Brown, P. L. Gorbarg, and Z. Ramazanov, "Rhodiola rosea - a phytomedicinal overview," Herbal Gram, vol. 56, pp. 40-52, 2002.

[22] A. Kucinskaite, V. Briedis, and A. Savickas, "Experimental analysis of therapeutic properties of Rhodiola rosea L. and its possible application in medicine," Medicina (Kaunas, Lithuania), vol. 40, no. 7, pp. 614-619, 2004 (Russian).

[23] A. Panossian, G. Wikman, and J. Sarris, "Rosenroot (Rhodiola rosea): traditional use, chemical composition, pharmacology and clinical efficacy," Phytomedicine, vol. 17, no. 7, pp. 481493, 2010.

[24] L. A. Khnykina and M. I. Zotova, "To the pharmacognostic study of Rhodiola rosea," Aptechnoe Delo, vol. 15, no. 6, pp. 34-38, 1966.

[25] A. S. Saratikov, E. A. Krasnov, L. A. Hnikina, and L. M. Duvidzon, "Introduction and chemical investigations biologically active substances from Rose root and chetyrehlepestnoy," News of AN SSSR, vol. 5, no. 1, pp. 54-60, 1967 (Russian).
[26] A. S. Saratikov and E. A. Krasnov, Rhodiola rosea-Valuable Medicinal Plant (Golden root), Tomsk, 3rd edition, 1987.

[27] V. V. Komar, Z. V. Karpliuk, S. M. Kit, L. V. Komar, and V. O. Smolins'ka, "Macro- and microelement composition of root extracts of Rhodiola rosea (golden root)," Farmatsevtychnyi Zhurnal, vol. 3, pp. 58-60, 1980 (Ukrainian).

[28] V. A. Kurkin, G. G. Zapesochnaya, U. N. Gorbunov, E. L. Nukhimowskii, A. I. Shreter, and A. N. Shchavlinskii, "Chemical investigations same species Rhodiola L. and Sedum L. and questions about their chemicals composition and taxonomy," Plant Resources, vol. 22, no. 3, pp. 310-319, 1986 (Russian).

[29] A. G. Dubichev, V. A. Kurkin, G. G. Zapesochnaya, and E. D. Vorontsov, "Chemical composition of the rhizomes of the Rhodiola rosea by the HPLC method," Chemistry of Natural Compounds, vol. 27, no. 2, pp. 161-164, 1991.

[30] M. Furmanowa, B. Kedzia, M. Hartwich et al., "Phytochemical and pharmacological properties of Rhodiola rosea L.," Herba Polonica, vol. 45, pp. 108-113, 1999.

[31] V. A. Kurkin and G. G. Zapesochnaya, "Chemical composition and pharmacological characteristics of Rhodiola rosea," Journal of Medicinal Plants, pp. 1231-1445, 1985.

[32] V. A. Kurkin and G. G. Zapesochnaya, "Chemical composition and pharmacological properties of Rhodiola rosea," Chemical and Pharmaceutical Journal (Moscow), vol. 20, no. 10, pp. 1231-1244, 1986.

[33] S. A. Patov, V. V. Punegov, and A. V. Kuchin, "Synthesis of the Rhodiola rosea glycoside rosavin," Chemistry of Natural Compounds, vol. 42, no. 4, pp. 397-399, 2006.

[34] G. G. Zapesochnaya and V. A. Kurkin, "Glycosides from alcohol extract from rhizomes of Rhodiola rosea," Chemical Natural Products, vol. 6, pp. 723-727, 1982 (Russian).

[35] V. A. Kurkin, G. G. Zapesochnaya, and A. N. Shchavlinskii, “Terpenoids of Rhodiola rosea rhizomes," Khimiya Prirodnykh Soedinenii, vol. 5, pp. 632-636, 1985.

[36] V. A. Kurkin, G. G. Zapesochnaya, A. N. Shchavlinskii, E. L. Nukhimovskii, and V. V. Vandyshev, "Method for determination of Rhodiola rosea rhizomes authenticity and quality," Khimiko-Farmatsevticheskii Zhurnal, vol. 19, pp. 185-190, 1985.

[37] A. T. Troshchenko and G. A. Kutikova, "Rhodioloside from Rhodiola rosea and Rhodiola quadrifida," Khimiya Prirodnykh Soedinenii, vol. 3, no. 4, pp. 244-249, 1967.

[38] R. I. Peshekhova, V. D. Gol'tsev, and L. A. Khnykina, "Determination of salidroside in Rhodiola rosea extracts," in Izuch. Lekarstvenii Rastenii Sib., Mezhvuz. Nauchnoe Konferencii, pp. 83-84, 1973.

[39] V. A. Kurkin, G. G. Zapesochnaya, A. A. Kiryanov et al., "The qualities of extract of rose root," Khimiko-Farmatsevticheskii Zhurnal, vol. 23, no. 11, pp. 1364-1367, 1989 (Russian).

[40] I. F. Satsiperova, I. A. Pautova, V. A. Kurkin, and G. G. Zapesochnaya, "Biologically active substances in Rhodiola rosea roots and rhizomes from Peterburg," Plant Resources, vol. 29, no. 2, pp. 26-31, 1993 (Russian).

[41] E. M. Antipenko and P. V. Kuznetsov, "Affinity-type polymer adsorbents in the study of physiologically active substances. XII. Separation and analysis of phenolic compounds in Rhodiola rosea L. extracts on adsorbents with phenolic ligands," Khimiko-Farmatsevticheskii Zhurnal, vol. 32, pp. 48-51, 1998 (Russian).

[42] P. T. Linh, Y. H. Kim, S. P. Hong, J. J. Jian, and J. S. Kang, "Quantitative determination of salidroside and tyrosol from the underground part of Rhodiola rosea by high perfomance liquid chromatography," Eksperimental'naia $i$ Klinicheskaia Farmakologiia, vol. 65, no. 6, pp. 57-59, 2002 (Russian). 
[43] G. G. Zapesochnaya, V. A. Kurkin, and A. N. Shchavlinskii, "Flavonoids of the epigeal part of Rhodiola rosea: II. Structures of new glycosides of herbacetin and of gossypetin," Khimiya Prirodnykh Soedinenii, vol. 4, pp. 496-507, 1985 (Russian).

[44] N. A. Nekratova, E. A. Krasnov, N. F. Nekratov, and S. I. Mikhailova, "Changes of quantitative contents of salidroside and tannins in underground organs of Rhodiola rosea L. in its natural habitats in Altai," Plant Resources, vol. 28, pp. 40-48, 1992 (Russian).

[45] E. P. Shirokov, D. Badgaa, and I. V. Kobozev, "Essential oil content in plants used in the production of tonics," Izvestiya Timiryazevskoi Sel'skokhozyaistvennoi Akademii, vol. 3, pp. 187-191, 1980 (Russian).

[46] V. N. Belov, T. V. Lavrova, N. G. Vashkevich, and A. Y. Mikhailov, "Extraction of essential oils from plant raw material by steam distillation," Russian Journal of Applied Chemistry, vol. 67, pp. 154-156, 1994.

[47] G. G. Yousef, M. H. Grace, D. M. Cheng, I. V. Belolipov, I. Raskin, and M. A. Lila, "Comparative phytochemical characterization of three Rhodiola species," Phytochemistry, vol. 67, no. 21, pp. 2380-2391, 2006.

[48] M. Ganzera, Y. Yaylaq, and I. A. Khan, "Analysis of the marker copounds of Rhodiola rosea L. (golden root) by reversed phase high performance liquid chromatography," Archives of Pharmacal Research, vol. 23, no. 4, pp. 349-352, 2000.

[49] J. Rohloff, "Volatiles from rhizomes of Rhodiola rosea L," Phytochemistry, vol. 59, no. 6, pp. 655-661, 2002.

[50] L. N. Evstatieva and T. A. Revina, "Investigation of Polyphenols in Rhodiola rosea Groupe polyphenols," Journees Internationales d'Etudes, vol. 12, pp. 127-128, 1984.

[51] V. Komarova, Flora USSR, vol. 9, 1961.

[52] "Flora of Canadian Artic Archipelago," ver. 29, 2003.

[53] Flora of Republic of Bulgaria, vol. 4, Bulgarian Academy of Sciences, Sofia, Bulgaria, 1970.

[54] N. I. Igosheva and E. A. Shurova, "Spread of some wild grown medicinal and strawberry species in Tyumen," Plant Resources, vol. 2, pp. 57-62, 2003 (Russian).

[55] I. Kajmakanova, "Ecologically and phytochemical investigation of Rhodiola rosea L. (family Crassulaceae) in Bulgaria (in natural ant cultural conditions)," in Scientific publications from Student scientific conference "Conservation of the biological diversity and management of the protected areas", pp. 3-9, Sofia, Bulgaria, 2005.

[56] “Bulgarian Law Gazette (State newspaper),” vol. 77, 2002.

[57] "Bulgarian Law Gazette (State newspaper)," vol. 29, 2000.

[58] V. A. Moryakina, T. P. Sviridova, T. N. Belyaeva, G. Ya. Stepanuk, V. P. Amelchenkov, and N. S. Zinner, "Conservation of plant biodiversity flora from Siberia botanical garden," Tomskova GOSUniversity, Nespapers VOGÆS, vol. 12, no. 4, pp. 555-562, 2008.

[59] R. Jens, Cultivation of herbs and medicinal plants in Norwayessential oil production and quality control, Ph.D. thesis, The Plant Biocentre, Department of Biology, Faculty of Natural Sciences and Technology, Norwegian University of Science and Technology, NTNU, Trondheim, Norway, 2003.

[60] S. Platikanov and L. Evstatieva, "Introduction of wild golden root (Rhodiola rosea L.) as a potential economic crop in Bulgaria," Economic Botany, vol. 62, no. 4, pp. 621-627, 2008.

[61] V. N. Kaftanat, M. V. Bodrug, and V. N. Floryia, "Enhanced multiplication of Rhodioloa rosea in Moldova," in Proceedings of the 2nd National Conference on Medicinal Botany, p. 64, Kiev, Ukraine, 1988.
[62] E. B. Kirichenko, S. S. Rudenko, B. M. Baglaj, and U. G. Masikevich, "Leaf culture from invitro propagated Rhodiola rosea," Bulletin GBS, RAN, vol. 169, pp. 50-54, 1994 (Russian).

[63] O. F. Bazuk, G. G. Baraneckii, and L. V. Fedyaj, "Micropropagation of rose root," in Proceedings of the Conference of Investigations of Ontogenesis Natural and Cultural Flora in Botanical Garden Eurasia, pp. 6-8, Kiev, Ukraine, 1994.

[64] T. Murashige and F. Skoog, "A revised medium for rapid growth and bio assays with tobacco tissue cultures," Physiologia Plantarum, vol. 15, no. 3, pp. 473-497, 1962.

[65] M. Furmanowa, H. Oledzka, M. Michalska, I. Sokolnicka, and D. Radomska, "Rhodiola rosea L. (Roseroot): in vitro regeneration and the biological acivity of roots," in Biotechnology in Agriculture and Forestry, vol. 33 of Medicinal and Aromatic Plants VIII, pp. 412-426, Springer, Berlin, Germany, 1995.

[66] V. Kapchina-Toteva and L. Sokolov, "In vitro micropropagation of Rhodiola rosea L.," Annuaire de L'Universite de Sofia "St. Kliment Ohridski”, vol. 88, no. 4, pp. 222-226, 1997.

[67] W. B. Yin, W. Li, G. S. Du, and Q. N. Huang, "Studies on tissue culture of Tibetan Rhodiola rosea," Acta Botanica BorealiOccidentalia Sinica, vol. 24, pp. 1506-1510, 2004.

[68] L. Hai-jun, G. Bin, Y. Qiong, L. Yu-jun, and L. Chun-Zhao, "Tissue culture of four Rhodiola species," Acta Botanica BorealiOccidentalia Sinica, pp. 207-210, 2006.

[69] K. Tasheva and G. Kosturkova, "Bulgarian golden root in vitro cultures for micropropagation and reintroduction," Central European Journal of Biology, vol. 5, no. 6, pp. 853-863, 2010.

[70] M. M. Ishmuratova, "Clonal micropropagation of Rhodiola rosea L. and $R$. iremelica Boriss. in vitro," Plant Resources, vol. 34, no. 1, pp. 12-23, 1998 (Russian).

[71] S. C. Debnath, "Zeatin and TDZ-induced shoot proliferation and use of bioreactor in clonal propagation of medicinal herb, roseroot (Rhodiola rosea L)," Journal of Plant Biochemistry and Biotechnology, vol. 18, no. 2, pp. 245-248, 2009.

[72] G. Gogu, M. Hârțan, D. Nicuță, and D. Maftei, "Preliminary data regarding Rhodiola rosea L. in vitro," in Proceedings of the Scientific Papers of the 5th Conference on Medicinal and Aromatic Plants of Southeast European Countries (CMAPSEEC '08), pp. 1-6, Brno, Czech Republic, September 2008.

[73] B. Dimitrov, K. Tasheva, N. Zagorska, and L. Evstatieva, "In vitro cultivation of Rhodiola rosea L." Genetics and Breeding, vol. 32, no. 1-2, pp. 3-6, 2003.

[74] K. Tasheva, N. Zagorska, B. Dimitrov, and L. Evstatieva, "In vitro cultivation of Rhodiola rosea L.", in Proceedings of the International Scientific Conference, vol. 2, pp. 161-165, Octobre 2003.

[75] Z. Nurazah, M. Radzali, A. Syahida, and M. Maziah, "Effects of plant growth regulators on callus induction from Cananga odorata flower petal explant," African Journal of Biotechnology, vol. 8, no. 12, pp. 2740-2743, 2009.

[76] M. M. Ishmuratova, "Effect of Rhodiola rosea plant extracts on the in vitro development of Rhodiola rosea L. and Rhodiola iremelica Boriss Explants," Biotekhnologiya, vol. 6, pp. 52-56, 2002 (Russian).

[77] K. Tasheva and G. Kosturkova, Rhodiola rosea in vitro cultures peculiarities, series F, Biotechnology, Bucharest Romania, 2010.

[78] M. Bozhilova, L. Evstatieva, and K. Tasheva, "Salidroside content in in vitro propagated Rhodiola rosea L.", in Proceedings of the 5th Conference on Medicinal and Aromatic Plants of Southeast European Countries (CMAPSEEC '08), Brno, Czech republic, 2008. 
[79] K. Tasheva and G. Kosturkova, "Rhodiola rosea L. in vitro plants morphophysiological and cytological characteristics," Romanian Biotechnological Letters, vol. 16, no. 6, pp. 79-85, 2011.

[80] M. Furmanowa, M. Hartwich, A. W. Alfermann, W. Koźmiński, and M. Olejnik, "Rosavin as a product of glycosylation by Rhodiola rosea (roseroot) cell cultures," Plant Cell, Tissue and Organ Culture, vol. 56, no. 2, pp. 105-110, 1999.

[81] Z. György, A. Tolonen, M. Pakonen, P. Neubauer, and A. Hohtola, "Enhancing the production of cinnamyl glycosides in compact callus aggregate cultures of Rhodiola rosea by biotransformation of cinnamyl alcohol," Plant Science, vol. 166, no. 1, pp. 229-236, 2004.

[82] Z. György, Glycoside production by in vitro Rhodiola rosea cultures, Ph.D. thesis, Acta Universitatis Ouluensis C Tehnica 244, Oulu, Finland, 2006.

[83] A. Krajewska-Patan, A. Mscisz, B. Kedzia, and J. Lutomski, "The influence of elicitation on the tissue cultures of roseroot (Rhodiola rosea)," Herba Polonica, vol. 48, no. 2, pp. 77-81, 2002.

[84] A. Krajewska-Patan, M. Dreger, A. Lowicka et al., "Chemical investigation of biottransformed Rhodiola rosea callus tissue," Herba Polonica, vol. 53, no. 4, 2007.

[85] A. Krajewska-Patan, M. Dreger, A. Lowicka et al., "Preliminary pharmacological investigation of biotransformed roseroot (Rhodiola rosea) callus tissue," Herba Polonica, vol. 54, no. 3, 2008.

[86] K. Tasheva, In vitro cultures of Rhodiola rosea-investigations of possibilities to propagation and conservation of the species and production of biologically active substances, Ph.D. thesis, Sofia, Bulgaria, 2011.

[87] S. Chang-zhong, H. Tie-Qiang, B. H. Y. Ying-Jin, and J. Yan, "Effects of plant growth substances on induction and culture of callus from Rhodiola quadrifida," China Journal of Chinese Materia Medica, vol. 30, no. 16, pp. 1237-4016, 2005 (Chinese).

[88] W. Li, G.-S. Du, and Q.-N. Huang, "Salidroside contents and related enzymatic activities in Rhodiola kirilowii callus," Acta Botanica Boreali-occidentalia Sinica, vol. 25, no. 8, pp. 16451648, 2005.

[89] S. Hong, T. Fang, G. Yan, and Z. Rui-lin, "Callus induction and plant regeneration in Rhodiola coccinea," Journal of Xinjiang Agricultural University, vol. 31, no. 3, pp. 58-61, 2008 (Chinese).

[90] X. Jianfeng, Z. Yan, H. Aiming, and F. Pusun, "Induction and culture of calli from Rhodiola sachalinesis A. Bor.," Chinese Journal of Applied and Environmental Biology, vol. 1, pp. 1925, 1995 (Chinese).

[91] L. Jianfeng, Y. Xiufeng, L. Xia, and C. Yunqing, "Callus induction and plant regeneration from leaf explants of Rhodiola sachalinesis A. Bor.," Journal of Northeast Forestry University, 2007 (Chinese).

[92] L. Jianfeng, Y. Xiufeng, C. Yun-Qing, and Z. Xiao-Mei, “Cryopreservation of calli by vitrification and plant regeneration of Rhodiola sachalinesis," Journal of Beijing Forestry University, 2007 (Chinese).

[93] L. Jian-Feng, C. Yun-Qing, and C. Zhi-Wen, "Protoplast isolation and plant regeneration from leaves of Rhodiola sachalinesis," Chinese Traditional and Herbal Drugs, vol. 7, pp. 20102014, 2009 (Chinese).

[94] S. Wu, Y. Zu, and M. Wu, "High yield production of salidroside in the suspension culture of Rhodiola sachalinensis," Journal of Biotechnology, vol. 106, no. 1, pp. 33-43, 2003.
[95] W. Yun-Mei, "Tissue culture and rapid propagation of Yunnan Wild Rhodiola crenulata," Journal of Anhui Agricultural Sciences, vol. 17, pp. 57-61, 2009 (Chinese). 

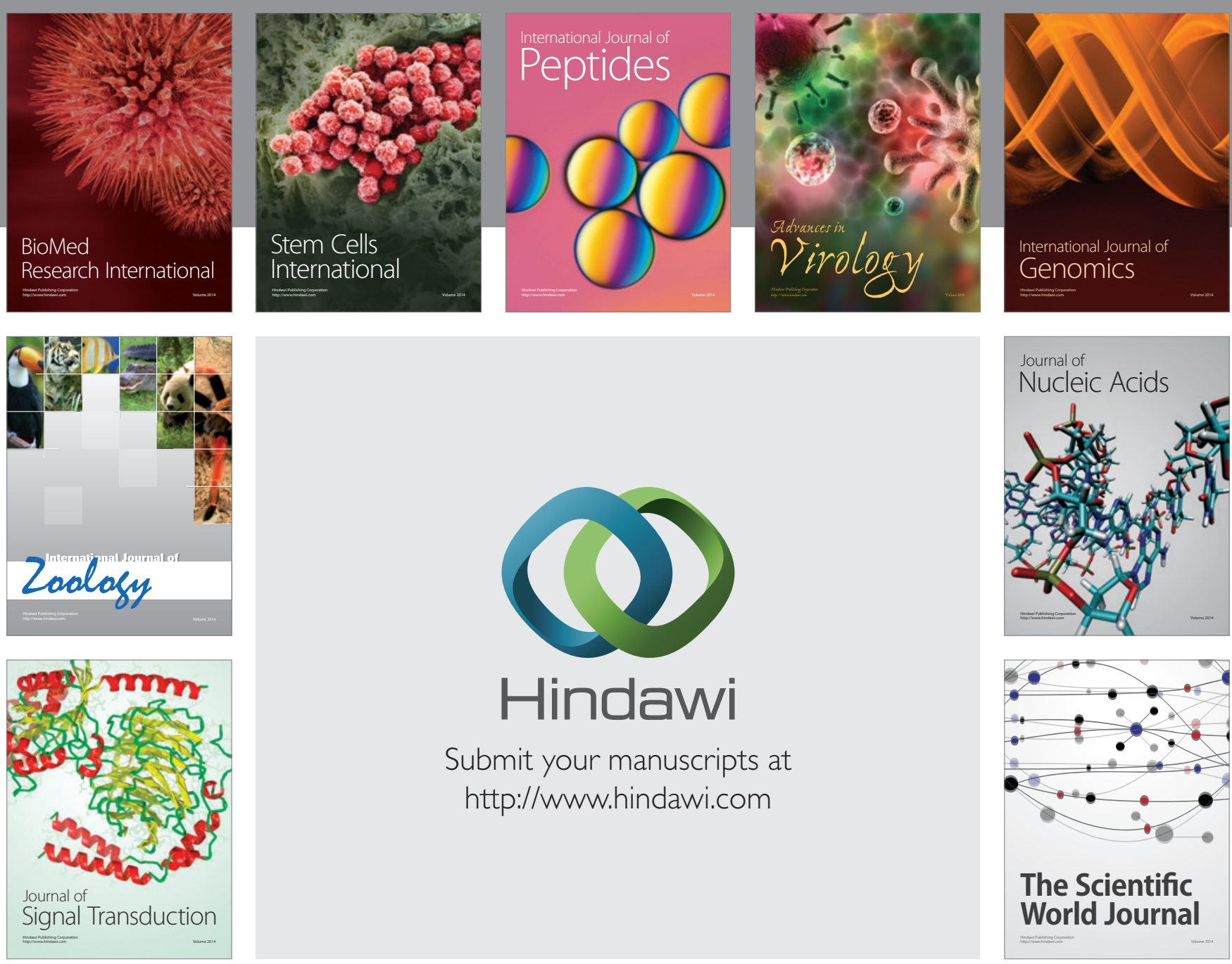

Submit your manuscripts at

http://www.hindawi.com
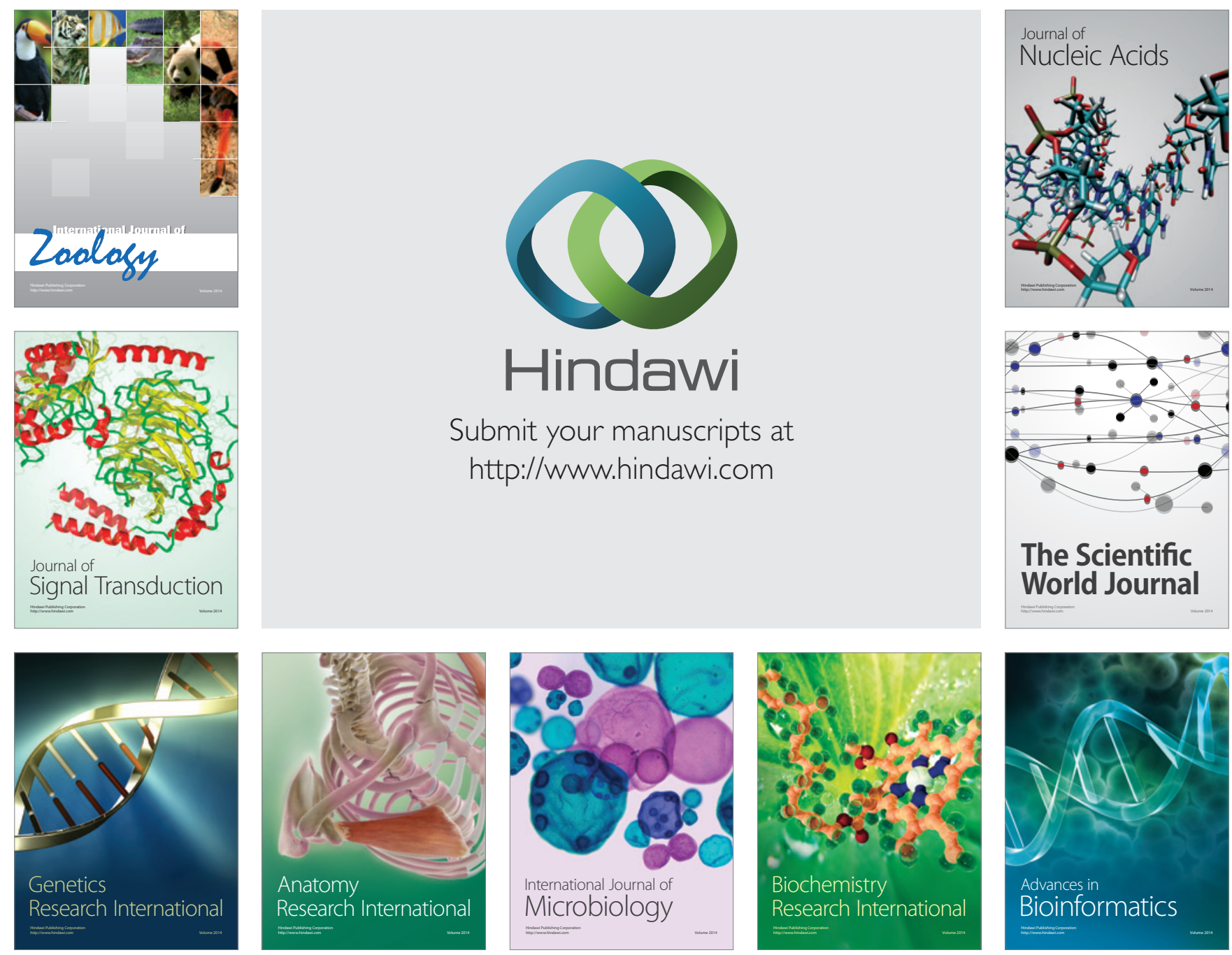

The Scientific World Journal
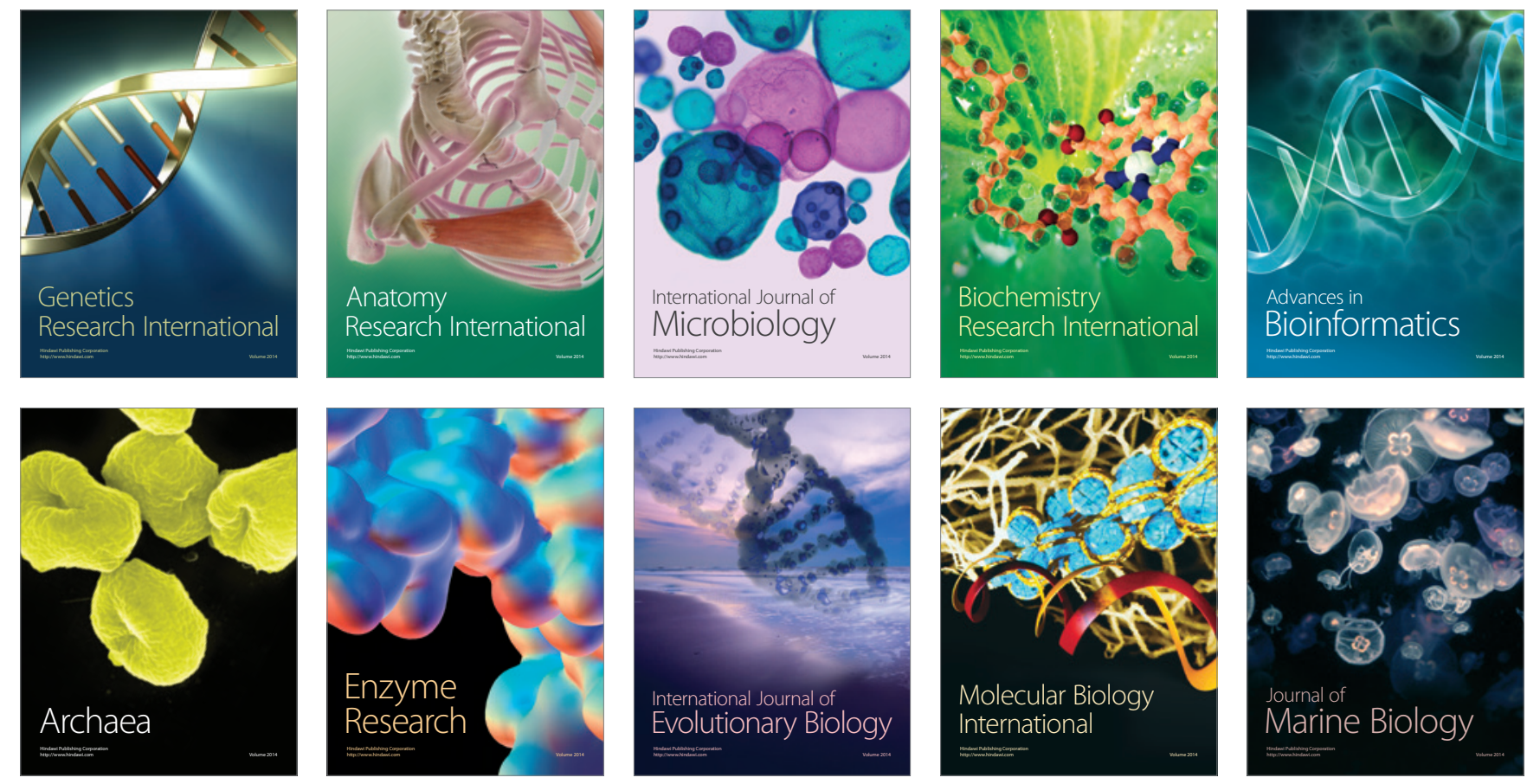